\title{
The Project and Its Antecedents
}

\author{
Dagnosław Demski \\ Institute of Archaeology and Ethnology, \\ Polish Academy of Sciences, Warsaw
}

The publication of this special issue provides a great opportunity to underline the importance of the long-standing and successful cooperation between scholars and academic institutions from Hungary and Poland, which resulted in a series of joint academic events and publications.

The first international project, the result of a fruitful cooperation between the Institute of Archaeology and Ethnology of the Polish Academy of Sciences in Warsaw and the Institute of Ethnology of the Hungarian Academy of Sciences in Budapest, was dedicated to the visual representations of otherness in Central and Eastern Europe (CEE) in the nineteenth and twentieth centuries. It led to the publication of four English-language books between 2010 and 2017. The four volumes gathered articles written by scholars from different countries, but the work could not have been accomplished without the enormous contributions of the main editors: Kamila Baraniecka-Olszewska, Ildikó Sz. Kristóf, Liisi Laineste, Anelia Kassabova, and myself (see Kabzińska's review in this issue).

The special issue that is now in the hands of the reader is part of a larger scientific project entitled Staged Otherness. Human Oddities in Central and Eastern Europe, 1850-1939. Besides my personal engagement and role as a project leader, the main contribution to the project was made by Dominika Czarnecka and Kamila BaranieckaOlszewska. The project, which started in 2016, has been funded by National Science Center grant no. UMO-2015/19/B/HS3/02143. Researchers from European countries focused their interest on staged otherness in nineteenth- and twentieth-century EastCentral Europe, particularly ethnographic and freak shows. Although this cultural phenomenon has been studied thoroughly by American and Western European scholars, a comprehensive research in the East-Central European context has never been conducted. By approaching ethnographic and freak shows from the perspective of local voices, we seek to contribute to a more nuanced and diversified understanding of the nature and effects of ethnographic and freak shows in the CEE.

Thanks to this ongoing project, we are pleased to continue the successful cooperation between Polish and Hungarian researchers. Since 2016, we have organized two international conferences. The first one, entitled Staged Otherness. Human Oddities in 
Central and Eastern Europe, c. 1850-1939, was held in Warsaw October 25-27, 2017. It was organized by the Institute of Archaeology and Ethnology of the Polish Academy of Sciences and the Institute of Art of the Polish Academy of Sciences. Twenty-two scholars from nine countries participated in the event. The second conference, entitled Staged Otherness, c. 1850-1939. East-Central European Responses and Contexts, was held in Budapest January 16-18, 2019. The event, organized by the Central European University and the Institute of Ethnology of the Research Centre for the Humanities of the Hungarian Academy of Sciences, could not have happened without the excellent cooperation and full engagement of László Kontler and Ágnes Fülemile. Twenty-one scholars from ten countries participated in the conference.

The project resulted in numerous scientific publications with the contributions of both Polish and Hungarian scholars. Besides this special issue of Acta Ethnographica Hungarica edited by Izabela Kopania, several articles in Polish have been already published in academic journals. In 2020, a special issue of the Journal of East Central Europe edited by Dagnosław Demski, Dominika Czarnecka, and Kamila BaranieckaOlszewska will be published. The final result of the project will be a book dedicated specifically to ethnographic shows in the CEE. Its publication is planned for 2020.

I would like to thank everyone who contributed to this and previous projects. Only with the joint effort of many wonderful people and great scholars can we make such big ideas happen. 